\title{
HUBUNGAN FREKUENSI OLAHRAGA AEROBIK DENGAN KEJADIAN DISMENORE PADA REMAJA PUTRI
}

\section{THE RELATIONSHIP BETWEEN FREQUENCY OF AEROBIC WITH DYSMENORRHEA ON ADOLESCENT GIRLS}

\author{
Rusiana Sri Haryanti ${ }^{1}$, Danik Kurniawati ${ }^{2}$ \\ Prodi D III Kebidanan STIKES PKU Muhammadiyah Surakarta \\ email: rusianamolyn@gmail.com dan email: danikkurniawati95@gmail.com
}

\begin{abstract}
Abstrak
Dismenore adalah nyeri saat haid, biasanya dengan rasa kram dan terpusat di abdomen bawah. Keluhan nyeri haid dapat terjadi bervariasi dari yang ringan sampai berat. Angka kejadian dismenore di Jawa Tengah mencapai 56 \%. Latihan olahraga aerobik mampu mengurangi gejala gangguan menstruasi seperti dismenore.Berdasarkan studi pendahuluan yang dilakukan di Aerobic Syariah Surakarta, mayoritas remaja tidak teratur mengikuti senam aerobik mengalami dismenore.Mengetahui hubungan frekuensi olahraga aerobik dengan kejadian disminore pada remaja putri.Metode penelitian ini menggunakan analisis korelasi dengan pendekatan cross sectional. Sample pada penelitian ini yaitu 30 responden dengan tekhnik sampel menggunakan purposive sampling. Instrumen penelitian menggunakan cheklist. Analisa data menggunakan chi square.Mayoritas remaja dengan frekuensi olahraga aerobik tidak teratur yaitu ada 19 orang $(63,3 \%)$, sedangkan mayoritas dengan kejadian nyeri dismenore dalam kategori sedang yaitu ada 15 orang $(50.0 \%)$. Nilai $N=30, d f=2$ dan $\alpha=5 \%$ diperoleh $x^{2}$ hitung 7,177 , sedangkan $x^{2}$ tabel 5,99, sehingga disimpulkan bahwa $x^{2}$ hitung $(7,177)>x^{2}$ tabel $(5,99)$ ha diterima dan ho ditolak. Terdapat hubungan antara frekuensi olahraga aerobik dengan kejadian dismenore pada remaja putri.
\end{abstract}

Kata Kunci: Frekuensi olahraga, kejadian dismenore, remaja putri.

\begin{abstract}
Dysmenorrhea is pain on menstruation, usually with a sense of cramp and centralized in the abdomen bottom. Complaints of painful menstruation can occur varying from a light to severe. Incidence dysmenorrhea in central java reached 56\%. Exercise sports aerobic can reduce symptoms menstrual disorders as dysmenorrhea. Based on the introduction study which was done in Aerobic Syariah Surakarta, the majority of teenagers who followed gymnastic aerobic irregularly experienced dysmenorrhea. It is known that there was a correlation between the frequency of sports aerobic with the genesis disminore in adolescent girls. The method of this research used analysis correlation with cross sectional approach. The sample was 30 respondents taken with purposive sampling. The instrument of the research was cheklist.Data analyzed by using chi square.The majority of the youth with the frequency of sports aerobic irregular were 19 people ( $63.3 \%$ ), meanwhile, majority of with a pain dysmenorrhea in medium category were 15 people ( $50.0 \%$ ). Value $n=30, d f=2$ and $\alpha=5 \%$ obtained $x^{2}$ count 7,177 , while $x^{2}$ table 5,99 , so that it is concluded that $x^{2}$ count $(7,177)>x^{2}$ table $(5,99) H a$ was received and Ho was rejected.There was a correlation between the frequency of sports aerobic with the genesis dysmenorrhea in adolescent girls.
\end{abstract}

Keywords: Frequency sports, the incident dimenore, adolescent girls. 


\section{PENDAHULUAN}

Prevalensi dismenore dalam beberapa penelitian menunjukkan frekuensi yang cukup tinggi. Dalam suatu systemic review WHO, rata-rata insidensi terjadinya dismenore pada wanita muda antara 16,8 - 81\%. Di Inggris dilaporkan 45 97\% wanita dengan keluhan dismenore, dimana prevalensi hampir sama ditemui di negara-negara Eropa. Prevalensi terendah dijumpai di Bulgaria $(8,8 \%)$ dan prevalensi tertinggi di negara Finlandia (94\%) (Latthe, et al, 2006).

Di Indonesia angka kejadiannya diperkirakan 45-59 \% di kalangan wanita usia produktif. Angka kejadian dismenore di Jawa Tengah mencapai $56 \%$, walaupun pada umumnya tidak berbahaya, namun acapkali dirasa mengganggu bagi wanita yang mengalaminya (Riyanto, 2009).

Dismenore adalah nyeri saat haid, biasanya dengan rasa kram dan terpusat di abdomen bawah. Keluhan nyeri haid dapat terjadi bervariasi mulai dari yang ringan sampai berat (Suparto, 2011 ). Sebagian besar wanita, latihan olahraga aerobik mampu mengurangi gejalagejala gangguan menstruasi seperti dismenore yaitu mengurangi kelelahan dan stress. Latihan ini dapat berupa jalan cepat, jogging, senam, bersepeda, dan berenang. Latihan olahraga aerobik juga mampu memperbaiki kesehatan hati atau jantung dan mampu membantu mengendalikan tekanan berat, serta latihan fisik juga meningkatkan rangsangan simpatis yaitu suatu kondisi yang menurunkan detak jantung dan mengurangi sensasi cemas (Laila, 2011 ).

Olahraga merupakan salah satu aktivitas yang bisa memberikan banyak manfaat bagi tubuh kita.Latihan fisik juga bisa membantu kita untuk menurunkan tingkat stress. Dengan berolahraga secara teratur, hormon stress akan menurun dan endorphin akan meningkat sehingga kita akan merasa nyaman setelah melakukan aktivitas fisik (Linda. 2015 ). Dengan olahraga dapat meningkatkan pasokan darah ke organ reproduksi sehingga memperlancar peredaran darah.Olahraga teratur seperti jalan cepat, jogging, berlari, berenang, bersepeda atau aerobik dapat memperbaiki kesehatan secara umum dan menjaga siklus menstruasi agar tetap teratur.Beberapa wanita mencapai keringanan melalui olahraga, yang tidak hanya mengurangi stress tapi juga meningkatkan produksi endorphin di otak, penawar sakit alami tubuh.Tidak ada pembatasan aktifitas selama haid. Olahraga latihan aerobik dapat membantu memproduksi bahan alami yang dapat memblok rasa sakit ketika haid (Proverawati \& Misaroh, 2009).

Salah satu jenis olahraga yang paling banyak diikuti oleh remaja adalah aerobic. latihan olahraga aerobik mampu mengurangi gejalagejala gangguan menstruasi seperti dismenore yaitu mengurangi kelelahan dan stress. Dalam hal ini, terapi penurunan dismenore yang berupa latihan aerobik ini merupakan salah satu teknik relaksasi. Olahraga atau latihan fisik dapat menghasilkan hormon endorphin.Dimana olahraga terbukti dapat meningkatkan kadar endorphin empat sampai lima kali di dalam darah. Sehingga, semakin banyak melakukan senam atau olahraga maka akan semakin tinggi pula kadar endorphin (Suparto, 2011).

Berdasarkan studi pendahuluan yang dilakukan pada tanggal 29 Desember 2015 di Aerobic Syariah Surakarta, pada 10 remaja yang sudah mengalami haid didapatkan 7 remaja mengalami dismenore dan 3 remaja tidak mengalami dismenore, dikarenakan jarang mengikuti olahraga aerobik, dengan frekuensi olahraga 1-2 kali dalam seminggu.

Tujuan penelitian ini adalah untuk mengetahui hubungan frekuensi olahraga aerobik dengan kejadian dismenore pada remaja putri di Aerobic Syariah Surakarta.

\section{METODE PENELITIAN}

Penelitian ini menggunakan metode penelitian cross sectional. Lokasi penelitian dilaksanakan di Aerobic Syariah Surakarta, pada bulan Mei sd Juni 2016. Populasi dalam penelitian ini adalah remaja yang berusia 18 sampai dengan 21 tahun yang mengikuti senam aerobik di Aerobic Syariah Surakarta dengan jumlah 50 orang dan besar sampelnya sebanyak 30 remaja putri. Teknik sampling yang digunakan adalah metode Purposive Sampling.

Pada penelitian ini yang menjadi variabel independent adalah frekuensi olahraga aerobik dan yang menjadi variabel dependent adalah kejadian disminore pada remaja putri. Analisa bivariat dalam penelitian ini menggunakan uji Chi Kuadrat.

\section{HASIL DAN PEMBAHASAN Karakteristik Responden}

Berdasarkan hasil penelitian yang dilakukan di Aerobic Syariah Surakarta, distribusi responden dapat disajikan dalam table berikut: 
Tabel 1. Distribusi Frekuensi Responden Berdasarkan Olahraga Aerobik

\begin{tabular}{ccc}
\hline Frekuensi Aerobik & Frekuensi & Presentase \\
\hline Tidak Teratur & 19 & $63,3 \%$ \\
Teratur & 11 & $36,7 \%$ \\
Total & 30 & $100,0 \%$ \\
\hline
\end{tabular}

Diketahui bahwa mayoritas dengan frekuensi olahraga aerobik tidak teratur yaitu ada 19 orang $(63,3 \%)$.

Tabel 2. Distribusi Frekuensi Responden Berdasarkan Kejadian Dismenore

\begin{tabular}{ccc}
\hline Nyeri Dismenore & Frekuensi & Presentase \\
\hline Ringan & 10 & $33,3 \%$ \\
Sedang & 15 & $50,0 \%$ \\
Berat & 5 & $16,7 \%$ \\
\hline Total & 30 & $100,0 \%$ \\
\hline
\end{tabular}

Diketahui bahwa mayoritas kejadian nyeri dismenore dalam kategori sedang yaitu ada 15 orang $(50.0 \%)$.

Tabel 3. Tabulasi Silang HubunganFrekuensi Olahraga Aerobik Dengan Kejadian Dismenore Pada Remaja Putri

\begin{tabular}{lcccc}
\hline Frekuensi & \multicolumn{3}{c}{ Nyeri Dismenore } & \multirow{2}{*}{ Total } \\
\cline { 2 - 4 } Aerobik & Ringan & Sedang & Berat & \\
\hline Tidak & 3 & 12 & 4 & 19 \\
Teratur & $10.0 \%$ & $40.0 \%$ & $13.3 \%$ & $63.3 \%$ \\
& 7 & 3 & 1 & 11 \\
Teratur & $23.3 \%$ & $10.0 \%$ & $3.3 \%$ & $36.7 \%$ \\
\hline \multirow{2}{*}{ Total } & 10 & 15 & 5 & 30 \\
& $33.3 \%$ & $50.0 \%$ & $16.7 \%$ & $100.0 \%$ \\
\hline
\end{tabular}

Diketahui bahwa hasil-hasil deskripsi tabulasi silang dimana dari 19 orang $(63,3 \%)$ yang tidak teratur olahraga aerobik, mayoritas dengan kejadian nyeri dismenore dalam kategori sedang yaitu ada 12 orang $(40,0 \%)$. Sedangkan dari 11 orang $(63,3 \%)$ yang teratur olahraga aerobik, mayoritas dengan kejadian nyeri dismenore dalam kategori ringan yaitu ada 7 orang $(23,3 \%)$. Berdasarkan uraian diatas ada kecenderungan bahwa semakin tidak teratur olahraga aerobik maka semakin besar resiko kejadian dismenore dalam kategori berat.

\section{Frekuensi Olahraga Aerobik}

Berdasarkan hasil penelitian yang diperoleh mengenai frekuensi olahraga aerobik pada tabel 1 menunjukkan bahwa responden melakukan olahraga aerobik tidak teratur (1-2 $\mathrm{x} /$ minggu) yaitu ada 19 orang $(63,3 \%)$ dan responden yang melakukan olahraga teratur (3-5 x/minggu) yaitu ada 11 orang $(36,7 \%)$.

Berdasarkan teori olahraga dapat meningkatkan pasokan darah ke organ reproduksi sehingga memperlancar peredaran darah. Olahraga teratur seperti jalan cepat, jogging, berlari, berenang, bersepeda atau aerobik dapat memperbaiki kesehatan secara umum dan menjaga siklus menstruasi agar tetap teratur. Beberapa wanita mencapai keringanan melalui olahraga, yang tidak hanya mengurangi stress tapi juga meningkatkan produksi endorphin di otak, penawar sakit alami tubuh. Tidak ada pembatasan aktivitas selama haid. Olahraga latihan aerobik dapat membantu memproduksi bahan alami yang dapat memblok rasa sakit ketika haid (Proverawati \& Misaroh, 2009).

Hal ini sesuai dengan Penelitian Afita bahwa dengan pemberian senam aerobik low impact sangat efektif untuk menurunkan dysmenorrhea primer.Hal ini sesuai dengan pendapat Rahma dalam Laila (2011) bahwa kejadian dysmenorrhea menurun pada remaja dengan adanya melakukan olahraga dibandingkan tidak melakukan olahraga, sehingga para remaja dianjurkan untuk melakukan olahraga. Adapun penelitian yang lain yaitu Yetti dalam Laila (2011) remaja yang rutin melakukan olahraga mengalami penurunan dysmenorrhea.

Berdasarkan penelitian di atas, penulis berasumsi bahwa sebagian besar remaja yang tidak teratur mengikuti senam aerobik berdasarkan wawancara mendalam kepada responden dengan alasan dikarenakan keterbatasan waktu serta biaya yang harus dikeluarkan untuk mengikuti senam aerobik. Sehingga banyak responden yang mengikuti senam areobik 1-2 kali dalam seminggu.Akan tetapi hal ini sesungguhnya dapat diatasi dengan melakukan olah raga sendiri dirumah, yaitu dapat berupa jalan cepat, jogging, senam, bersepeda, dan berenang. 


\section{Kejadian Dismenore Pada Remaja Putri}

Dalam penelitian ini diketahui bahwa mayoritas dengan kejadian nyeri dismenore dalam kategori sedang yaitu ada 15 orang (50.0\%). Dan minoritas responden dengan kejadian nyeri dismenore dalam kategori berat yaitu ada 5 orang $(16,7 \%)$. Jadi sebagian besar remaja putri mengalami nyeri yang masih tertolong dengan obat namun aktifitas seharihari terganggu.

Dismenore menyebabkan rasa nyeri pada perut bagian bawah, yang bisa menjalar kepunggung bagian bawah dan tungkai. Nyeri dirasakan sebagai kram yang hilang timbul atau sebagai nyeri tumpul yang terus-menerus ada (Manan, 2011). Biasanya, rasa nyeri mulai timbul sesaat sebelum atau selama menstruasi. Menurut Proverawati dan Misaroh (2009), penyebab dari Dismenore berdasarkan jenisnya yaitu dismenore primer antara lain disebabkan oleh beberapa faktor, (1) faktor psikis yaitu para wanita yang emosinya tidak stabil lebih mudah mengalami nyeri menstruasi, (2) faktor endokrin dimana timbulnya nyeri menstruasi diduga karena kontraksi rahim (uterus) yang berlebihan. (3) faktor prostaglandin yaitu nyeri menstruasi timbul karena peningkatan produksi prostaglandin oleh dinding rahim saat menstruasi. Anggapan ini mendasari pengobatan dengan anti prostaglandin untuk meredakan nyeri menstruasi. Dan faktor hormonal, faktor alergi dan lanlain.

Faktor penyebab terjadinya dismenore sekunder antara lain adalah endometriosis dan fibriods (myoma). Menurut Proverawati dan Misaroh (2009) beberapa faktor yang dianggap sebagai faktor resiko timbulnya rasa nyeri pada saat menstruasi yaitu; (1) Menstruasi pertama (menarche) diusia dini kurang dari 12 tahun), (2) wanita yang pernah melahirkan anak hidup (nulipara), (3) darah menstruasi berjumlah banyak atau massa menstruasi yang panjang, (4) perokok, (5) adanya riwayat nyeri menstruasi pada keluarga Obesitas atau kegemukan/ kelebihan berat badan.

Hasil penelitian ini sama dengan hasil penelitian yang dilakukan oleh Istiqomah (2009) tentang efektifitas senam aerobik dalam mengurangi dismenore pada remaja putri di SMU N 5 Semarang bahwa tingkat dismenore setelah melakukan senam dis- menore menunjukkan perubahan skala nyeri dengan skala nyeri ringan sebanyak 11 orang dan nyeri berat tidak ada.

Berdasarkan penelitian ini remaja yang mengalami dismenore dalam tingkat sedang sebanyak 15 orang. Penulis berasumsi bahwa hal ini dikarenakan remaja masih jarang melakukan olahraga aerobik.

\section{Hubungan frekuensi olahraga aerobik dengan kejadian dismenore pada remaja putri}

Berdasarkan hasil penelitian dari 19 orang $(63,3 \%)$ yang tidak teratur olahraga aerobik, minoritas dengan kejadian nyeri dismenore dalam kategori ringan yaitu ada 3 orang $(10,0 \%)$, dan mayoritas dengan kejadian nyeri dismenore dalam kategori sedang yaitu ada 12 orang $(40,0 \%)$. Sedangkan dari 11 orang $(63,3 \%)$ yang teratur olahraga aerobik, minoritas dengan kejadian nyeri dismenore dalam kategori berat yaitu ada 1 orang $(3,3 \%)$, dan mayoritas dengan kejadian nyeri dismenore dalam kategori ringan yaitu ada 7 orang $(23,3 \%)$.

Pengujian statistik menghasilkan nilai uji chi square $\left(\mathrm{X}_{\text {hitung }}^{2}\right)$ sebesar 7,177.Dimana $X_{\text {hitung }}^{2}>X_{\text {tabel }}^{2}(7,177>5,991)$ sehingga diputuskan bahwa ada hubungan signifikan antara frekuensi olahraga aerobik dengan kejadian dismenore pada remaja putri di Aerobic Syariah Surakarta.

Menurut Ramaiah (2006) menyebutkan bahwa, salah satu cara yang sangat efektif untuk mencegah nyeri dismenore ini adalah melakukan aktifitas olahraga. Beberapa latihan dapat meningkatkan pasokan darah ke organ reproduksi sehingga memperlancar peredaran darah. Olahraga teratur seperti berjalan kaki, jogging, berlari, bersepeda, renang atau senam aerobik dapat memperbaiki kesehatan secara umum dan menjaga siklus menstruasi yang teratur.

Berdasarkan uraian diatas ada kecenderungan bahwa semakin tidak teratur olahraga aerobik maka semakin besar resiko kejadian dismenore dalam kategori berat. Hal ini dikarenakan ketika seseorang melakukan olahraga atau senam, maka endorphin akan keluar dan ditangkap oleh reseptor di dalam hipothalamus dan sistem limbik yang berfungsi untuk mengatur emosi. Menurut Suparto (2011). Peningkatan hormone 
endorphin terbukti berhubungan erat dengan penurunan rasa nyeri.

Berdasarkan penelitian di atas maka penulis berasumsi bahwa hipotesis yang diajukan dalam penelitian ini yang menyatakan ada hubungan frekuensi olahraga aerobik dengan kejadian disminore pada remaja putri terbukti.

\section{SIMPULAN DAN SARAN \\ Simpulan}

Berdasarkan hasil penelitian yang telah dilakukan pada 30 responden remaja putri yang mengikuti senam aerobik di Aerobic Syariah Surakarta dapat disimpulkan sebagai berikut.

1. Mayoritas dengan frekuensi olahraga aerobik tidak teratur yaitu ada 19 orang $(63,3 \%)$.

2. Mayoritas dengan kejadian nyeri dismenore dalam kategori sedang yaitu ada 15 orang $(50,0 \%)$.

3. Ada hubungan signifikan antara frekuensi olahraga aerobik dengan kejadian dismenore pada remaja putri di Aerobic Syariah Surakarta, Dimana $X_{\text {hitung }}^{2}>X_{\text {tabel }}^{2}(7,177>$ $5,991)$.

\section{REFERENSI}

Istiqomah, 2009. "Efektivitas Senam Dismenore Dalam Mengurangi Dismenore Pada Remaja Putri Di Smu N 5 Semarang” diakses tanggal 2 Januari 2016. https:// core.ac.uk/download/pdf/11709709.pdf
Laila, Nur Najmi. 2011. Buku Pintar Menstruasi. Jogjakarta: Buku Biru.

Latthe. et al. 2006. WHO Systemic Review Of Prevalence Of Chronic Pelvic Pain : A Negleted Reproductive Health Morbidity. BMC Public Health: Birmingham. UK.

Linda. 2015. Senam Kecantikan. FlashBook: Yogyakarta

Manan, El. 2011. Miss V. Yogyakarta: Buku Biru.

Proverawati dan Misaroh. 2009. Menarche Pertama Penuh Makna. Yogyakarta: Nuha Medika.

Riyanto. 2009. Nyeri Haid pada Remaja.Majalah Gemari "Majalah Keluarga Mandiri". Edisi 12 November 2002. http://www. gemari.or.id/artikel/498.shtml

Ramaiah. 2006. Gangguan Menstruasi. Digiosa Media: Yogyakarta

Suparto, Ahmad. 2011. Efektifitas Senam Dismenore dalam Mengurangi Dismenorepada Remaja Putri.Phederal.Vol 4 No.1 